\title{
Qual a importância de se escrever uma biografia alimentar? Estudo a partir da
} análise de textos biográficos

\section{What is the importance of writing a food biography? Study from the analysis of biographical texts}

DOI: 10.46814/lajdv3n4-018

Recebimento dos originais: 01/05/2021

Aceitação para publicação: 31/06/2021

\section{Luiz Fernando Santos Escouto}

Doutor

Instituição de atuação atual: Centro Paula Souza - Faculdade de Tecnologia de Marília - SP - Curso de Tecnologia em Alimentos

Endereço completo: Rua Santa Helena 909, casa 135, quadra f - Jardim Alvorada / CEP: 17513-322 Marília-SP

Email: educacaoparaosabor@gmail.com

\section{RESUMO}

O objetivo do trabalho foi analisar as respostas dos acadêmicos concluintes do curso de Tecnologia em Alimentos à uma pergunta "qual a importância de se escrever uma biografia alimentar? Através desta pergunta textos narrativos produzidos foram analisados pelo método da análise narrativa. Das 39 produções escritas com textos narrativos breves geradas na aula de gastronomia a partir de quatro relatos autobiográficos apenas seis foram selecionadas. Os resultados da análise das narrativas mostraram que a importância da escrita da biografia alimentar reside no fato de ser um tema interdisciplinar entre ciência, tecnologia e arte e, por representar um modo sensibilizador de como foi feito o processo pedagógico através das lembranças alimentares, os acadêmicos inscreveram na memória gustativa suas histórias de vida.

Palavras-chave: biografia alimentar, análise narrativa, análise sensorial

\begin{abstract}
The objective of the work was to analyze the answers of the concluding students of the Food Technology course to the question "what is the importance of writing a food biography? Through this question narrative texts produced were analyzed by the narrative analysis method. Of the 39 written productions with short narrative texts generated in the gastronomy class from four autobiographical accounts only six were selected. The results of the analysis of the narratives showed that the importance of writing a food biography lies in the fact that it is an interdisciplinary theme between science, technology and art and, because it represents a sensitizing way of how the pedagogical process was done through food memories, the academics inscribed in the gustatory memory their life stories.
\end{abstract}

Keywords: food biography, narrative analysis, sensory analysis. 


\section{INTRODUÇÃO}

A gastronomia segundo Savarin (1989) e um estilo de vida, o resumo do mundo, e a diferença entre o prazer de comer e o prazer da mesa. Segundo Braune (2007), gastronomia é uma arte ou ciência que exige conhecimento e técnica de quem a executa e formação do paladar de quem a aprecia.

A gastronomia antes reservada ao recinto das cozinhas e a publicações, especializações, hoje já frequenta livremente todos os espaços do nosso cotidiano, a tal ponto que atraindo o interesse de um público cada vez maior e dos meios acadêmicos, foi parar nas salas de aulas de cursos superiores (SILVA, 2005).

Comer junto está profundamente associado aos laços afetivos entre os membros de uma família (ASSUNÇÃO, 2008). A memória gustativa é uma forma de memória que representa no nível individual o valor de permanência de vestígios passados (FLANDRIN \& MONTANARI, 1998; CORÇÃO, 2006).

A memória pode ser entendida como capacidade de relacionar um evento atual, com um evento passado do mesmo tipo, portanto, como uma capacidade de evocar o passado através do presente (JAPIASSU, 1996). Isso é bastante perceptível quando temos experiência de um sabor ou cheiro que percebíamos ou tínhamos enquanto crianças, mais tarde quando adultos ao sentirmos o cheiro ou sabor somos remetidos, voltamos ao passado e invocamos essa lembrança.

Existem lugares da memória, lugares particulares ligados a uma lembrança, que pode ser uma lembrança pessoal, mas também pode ter apoio no tempo cronológico. Pode ser, por exemplo, um lugar de férias na infância, que permaneceu muito forte na memória da pessoa, muito marcante, independente da data real em que a vivência se deu (POLLAK, 1992). A memória é a forma mais alta da imaginação humana, e não a simples capacidade de recordar. Se a memória se dissolver, consequentemente o homem se dissolve.

O Projeto Pedagógico é um conjunto de diretrizes e estratégias que expressam

e orientam a prática pedagógica do Curso. Trata-se da própria concepção do Curso que descreve um conjunto de conhecimentos, habilidades e atitudes a serem desenvolvidas nos alunos, além de se constituir em referencial que norteia a construção e a implementação do Curso, o que inclui a metodologia de desenvolvimento das diversas ações visando a mediação entre alunos e professores e entre esses e a comunidade. Assim, o Projeto Pedagógico de um Curso não é a mera organização curricular, pois reflete o posicionamento

institucional diante da realidade e do desenvolvimento da área de conhecimento e explicita as diversas ações interdisciplinares dos diversos Cursos da instituição.

O projeto pedagógico exprime, assim, a articulação existente entre a educação superior, o compromisso profissional e as transformações sociais, possibilitando antever as condições de ensino oferecidas. Ele articula e integra todas as atividades de ensino, pesquisa e extensão do curso, evitando 
a fragmentação de disciplinas; integra professores e cria conteúdos mais consistentes; permite também avançar na interdisciplinaridade, pois os conteúdos disciplinares passam a refletir aspectos da dialogicidade de forma a evitar a compartimentalização.

Marilia é hoje o maior Polo Industrial de Alimentos do Brasil, sendo uma ótima opção de investimento, que une oportunidades de desenvolvimento econômico a muita qualidade de vida. Através de pesquisa realizada pela FIPE-USP, Marilia ficou em $1^{\circ}$ lugar em Desenvolvimento do Estado. Foi apontada pela Unicef-ONU como Cidade Amiga da Criança e, também reconhecida pelo Instituto Ayrton Senna como cidade Modelo de Educação. É apontada como modelo em estrutura de ensino e como a quarta cidade mais segura do Estado. Tudo isso fez com que Marilia se transformasse em polo regional, com índice positivo na geração de empregos nas indústrias de alimentos e demais segmentos.

Por apresentar este perfil de crescimento na área alimentícia, o Centro Paula Souza instalou uma Faculdade de Tecnologia (FATEC) em Marilia, visando qualificar os trabalhadores que atuam no mercado de alimentos e abrindo novas oportunidades a todos que buscam ensino público com qualidade. A Fatec "Estudante Rafael Almeida Camarinha" (Fatec-Marilia) foi criada em 02 de marco de 2006, por meio do Decreto No 50.575, pelo Governador Geraldo Alckmim e iniciou suas atividades acadêmicas em 22 de marco de 2006 com o curso de Tecnologia em Alimentos e possui instalações próprias. Sua missão e "Formar profissionais competentes e éticos, capazes de enfrentar desafios na busca do desenvolvimento tecnológico, social e econômico" (Quadro I).

\section{ATOS LEGAIS REFERENTES AO CURSO}

Quadro I - Atos legais referentes ao curso Superior de Tecnologia em Alimentos, em 2006.

\begin{tabular}{|l|}
\hline Criação da FATEC: Decreto no 50.575/2006 \\
\hline Autorização: Parecer CEE no 181/2007 \\
\hline Reconhecimento: Portaria CEE/GP no 154/2007 \\
\hline Area de atuação \\
\hline Curso Superior de Tecnologia em Alimentos \\
\hline Curso Superior de Tecnologia em Mecanização em Agricultura de Precisão \\
\hline Pós-graduação em Gestão de Qualidade \\
\hline Programa Especial de Formação de Docentes 2011 - Esquema 1 \\
\hline
\end{tabular}


A ideia da introdução da disciplina "Gastronomia" na grade do curso de Tecnologia em Alimentos na Fatec/Marilia fez parte do conjunto dos últimos ajustes com relação a entrada de novas disciplinas, que compunha a tarefa de reestruturar e propor o novo currículo do curso. A principal alegação no período era de que a presença da disciplina poderia contribuir para, ao mesmo tempo, gerar uma atualização no currículo, o que favoreceria o diálogo de disciplinas classificadas como básicas e tecnológicas, e porque sendo a gastronomia uma disciplina que vinha de outro eixo tecnológico (hospitalidade, turismo e lazer) estaria em elaboração, numa perspectiva interdisciplinar, um novo olhar sobre o alimento e a alimentação bem como sobre as práticas de consumo, além disso motivar e atrair interessados em prestar o vestibular e, posteriormente, depois de percorrerem as nuanças teórico e práticas do curso de tecnologia em alimentos poderiam seguir estudos tecnológicos em nível de extensão e pós-graduação, no Brasil e no exterior.

A disciplina Gastronomia é recente no curso de Tecnologia em Alimentos na Fatec/ Marilia e data de fevereiro de 2012. Em sua ementa o curso visa preparar os acadêmicos para perceberem a Gastronomia como área interdisciplinar e de interface com a ciência, a tecnologia e a arte, e, por conseguinte, como marco referencial na geração de conhecimentos e saberes correlacionados a cultura alimentar e a educação do gosto.

Tem por objetivo oportunizar ao tecnólogo em alimentos a possibilidade de construir uma visão gastronômica amparada nas expressões mais significativas da cultura contemporânea a saber: as ciências humanas, as técnicas culinárias e a arte cinematográfica. Assim os conteúdos são trabalhados e agrupados colecionando encontros que tratam de leituras da Gastronomia através dos aspectos histórico-antropossociológicos e filosóficos. A coleção de encontros favorece a construção de leituras de si a partir da elaboração de biografias alimentares, leituras do outro que tem por base a linguagem do cinema por meio de filmes com foco gastronômico e leituras técnico-culinárias que subsidiam o desenvolvimento e acompanhamento das práticas gastronômicas.

\section{MATERIAL E MÉTODOS}

Foram coletadas 39 produções escritas com textos narrativos breves que foram gerados na aula de gastronomia onde foram trabalhados quatro relatos autobiográficos. Em seguida foi proposta aos acadêmicos a questão: Qual a importância de se escrever uma biografia alimentar na aula de gastronomia? Foi solicitado que os acadêmicos elaborassem seus registros no verso do instrumento de coleta de dados intitulado "pauta gastronômica". O procedimento para a seleção dos textos foi o sorteio aleatório e, foram selecionados seis. Os nomes dos acadêmicos são fictícios.

A análise narrativa dos textos gerados foi baseada nas leituras expressas por Amon \& Menasche (2008) e Figueiredo (2011), que auxiliaram na construção de uma perspectiva sobre a narrativa 
“alimentar", e as leituras de Carvalho (2003), Reis \& Antonello (2006) e Santos \& Dalto (2012) que discutiram a análise narrativa como metodologia.

\section{RESULTADOS E DISCUSSÃO}

Segundo Bolivar (apud Santos \& Dalto, 2012) ao analisar narrativas na área da

educação matemática afirmou que o objetivo da análise narrativa é produzir uma narrativa que apresenta sutilezas, singularidades dos dados que são produzidos por meio de um relato que oferece detalhes e peculiaridades do modo como os alunos produzem significados e constituem objetos que não podem ser expressos em definições, enunciados factuais ou proposições abstratas, como é o raciocínio logico formal.

Para Bolivar (apud Santos \& Dalto, 2012) a narrativa se caracteriza como:

[...] a qualidade estruturada da experiência entendida e vista como um relato; por outro (como enfoque de investigação), as diretrizes e formas de construir sentido, a partir de ações temporais e pessoais, por meio da descrição e análise de dados biográficos.

Garnica (apud Santos \& Dalto, 2012) afirma que a narrativa:

[...] expressa o que é possível dizer, num mundo onde esses ditos ressoam. As narrativas, registros da ação, permitem compreender algumas das crenças segundo as quais as pessoas agem. Permitem compreender que não há manutenção eterna nem alteração frequente: mostram que mantemos hábitos no esforço de rompê-los, que afirmamos querer romper hábitos para que possamos mantê-los. Ao fim e ao cabo, mostram que vivemos num mundo no qual esses discursos têm lugar e, de um modo ou outro, fazem sentido.

O modo narrativo de produzir conhecimento segundo Bolivar (apud Santos \& Dalto, 2012)

funciona

[...] por meio de uma coleção de casos individuais nos quais passa-se de um para outro, e não de um caso específico para uma generalização. A preocupação não é identificar cada caso em uma categoria geral; o conhecimento vem por analogia, de onde um indivíduo pode ou não ser similar a outros. O que importa são os mundos vividos pelos entrevistados, os sentidos singulares que expressam e as lógicas particulares de argumentação que apresentam.

Segundo Carvalho (2003) o auto-relato pode ser tomado como um locus privilegiado do encontro entre a vida íntima do indivíduo e sua inscrição numa história social e cultural. A biografia, ao tornar-se discurso narrado pelo sujeito autor e protagonista, instaura sempre um campo de renegociação e reinvenção identitária. Diz a autora que cultural ou individualmente o relato biográfico como ato narrativo proporciona ao sujeito sempre uma nova oportunidade de se apresentar, recontar e reposicionar-se, tecendo e (re)tecendo a intriga, sob os limites da discordância do destino, do tempo e do desconhecimento de si mesmo. 
Ao contar as suas histórias, as pessoas podem expressar sua identidade, relações e emoções. Além disso, podem ordenar e orientar eventos da vida e, em alguns casos, obter uma nova perspectiva desses eventos e podem resolver, frequentemente, problemas. Assim, a comunicação de histórias reveladoras é considerada um impulso humano natural. Seja qual for a abordagem utilizada, a função da análise narrativa é considerar o potencial das histórias para dar significado as vidas das pessoas e o tratamento dos dados como histórias (TORODE, apud Reis \& Antonello, 2006).

Segundo Figueiredo (2011) o contar histórias é uma das formas pelas quais os

sujeitos e as comunidades compreendem seu passado, seu presente e seu futuro. Nessa discussão da narrativa suscitam questões de como as narrativas sobre a comida (re)constroem a vida dos sujeitos, o que complexifica a questão, pois requer outro tipo de abordagem.

Partiu-se de produções escritas e foi construída uma narrativa que se constituiu

na articulação de características, particularidades e sutilezas a respeito do modo como os acadêmicos trabalharam com a questão proposta na aula de gastronomia. Abaixo são apresentados os textos narrativos breves que foram selecionadas para análise.

Para Santos a importância de escrever uma biografia alimentar é

“[...] que ela traz momentos inesquecíveis onde a família está presente à mesa, com variados cardápios e com a simplicidade de cada prato. Momentos que ficam na memória para sempre”.

A acadêmica relata que escrever passa pelo rememorar momentos em família à mesa, no consumo de comidas simples que ficaram na memória. DaMatta (1987) afirma "que saudade de falar aquela língua que é como o ar que eu respiro e de comer aquela comida que, além de me nutrir, traz à tona gostos e cheiros que estão enfurnados dentro do meu ser".

Para Souza a importância de escrever uma biografia alimentar reside:

“[...] na descrição das sensações e lembranças que se teve e ressaltar os hábitos, costumes e a questão cultural que vem se perdendo ao longo do tempo, já que muitos alimentos e preparações vem sendo substituídos por industrializados pela facilidade e acessibilidade, levando-se em consideração que nós temos cada dia menos tempo para nos dedicar a cozinha”.

Para Silveira a importância de escrever uma biografia alimentar é:

“[...] uma forma de resgatar lembranças muitas vezes perdidas, trazer a memória momentos em família, conversas, uma forma de resgatar a história, infâncias, momentos únicos e bons. Saber de onde veio e lembrar o porquê de certas características pessoais."

Em ambos os relatos, ao narrarem a importância da lembrança para a memória, nos escritos ganham valor hábitos e costumes que tentam resgatar a história singular vivida da infância a vida adulta em família, contudo, a comida moderna parece já não mais servir como espelho. Assim, segundo Amon 
e Menasche (2008) a relação que se estabelece entre a comida e a memória estão fundamentadas na ideia de que a comida tem uma dimensão comunicativa. A comida constitui assim um veículo para manifestar significados, emoções, visões do mundo e identidades. Para Bernardo (apud Figueiredo, 2011) lembrar e narrar são ações que ocorrem simultaneamente. Em outras palavras elas são indissociáveis.

Para Azevedo a importância de escrever uma biografia alimentar se traduz num

“[...] conhecimento do seu próprio eu, de suas lembranças. Saber profundamente o que se está comendo em uma refeição".

Ao relatar sobre o saber o que se come numa refeição relacionada ao conhecer-se, fica nítida a importância do escrever como tradução da construção subjetiva da identidade. Para Pollak (1992) há uma relação entre memória e a própria identidade, sendo a memória um fenômeno construído consciente ou inconsciente, como resultado do trabalho de organização individual ou socialmente. Do mesmo modo Carlos (2009), define a identidade como uma imagem que a pessoa adquire ao longo da vida referente a ela mesma, a imagem que ela constrói e apresenta a outros e a si própria, onde o sujeito acredita na sua representação e, também, da percepção que este quer que os outros tenham de sua vida e identidade.

Para Valenciano a importância de escrever uma biografia alimentar consegue:

“[...] trazer a lembrança do passado para o presente em pequenos detalhes, que vão desde uma simples refeição, [...] um bate-papo onde está reunida toda a família em volta de uma mesa farta ou não. Mas a simplicidade de se fazer um bom prato com toque simples e que fica na memória para sempre e, quando lembramos nos enche de emoção e alegria. Tempos que não voltam mais.”

A importância de escrever reside na capacidade de revisitar o passado, que atualizado está presente em breves porções junto a família em torno da mesa, porque enquanto se deliciam fortalecem os vínculos, ao conversarem refazem o memorial narrativo do simples e seus nuances. Graças ao compartilhamento de experiências vividas que evidenciam sensações, sentimentos, conflitos e a subjetividade dos envolvidos no processo que este compartilhar em volta da mesa se produz como fazendo parte de uma experiência em educação estética (DE ARRUDA; DE DEUS, 2021). Por isso para Bernardo (1998) a narrativa é a expressão da memória, (...) e elementos novos são constantemente incorporados tornando-se próprios de uma determinada narrativa, muitas vezes, a narrativa vai além, incorporando como memória, situações vividas ou imaginadas pelo "outro" e narradas como se as tivesse vivido, uma vez que há concordância e coerência com os seus pensamentos, pois a narrativa não se interessa pelo puro em si como a informação, e sim por essas construções de si que o sujeito faz 
bem como da representação de sua identidade. Do mesmo modo para Figueiredo (2011) o ato de comer junto - é um comportamento não automático que se liga de modo muito íntimo a nossa sobrevivência e as nossas emoções. Mesmo por circunstâncias impositivas os hábitos alimentares continuam sendo veículos de profunda emoção e carregada de profundos laços afetivos que podem ser levados na memória.

Para Lima a importância de escrever uma biografia alimentar se deve ao fato:

“[...] de nos remeter, principalmente, as lembranças do passado, coisas comuns como almoço em família, cada vez mais raro, e que nos permite refletir sobre nossas atitudes e comportamentos nos dias atuais. Resgatar valores, princípios, cultura e tradição familiar fazem parte de uma boa biografia alimentar e fortalecem os sentimentos e a memória."

Segundo o relato, a importância de escrever contempla ao mesmo tempo as lembranças de um passado que já não mais existe e faz parar e pensar o que aconteceu com o comportamento alimentar não só daquilo que pode ser percebido no imediato, mas toda a cultura e nela a herança culinária, tradição e memória que puderam ser trazidos a consciência. Segundo Bosi (apud Figueiredo, 2011) a memória aparece como uma força subjetiva ao mesmo tempo profunda e ativa, latente e penetrante, oculta e invasora. Para Figueiredo (2011) o caldo básico da relação entre comida e memória é a cultura. Desta maneira podemos compreender que os alimentos não são apenas comidos, mas também pensados. Assim para Neto (apud Figueiredo, 2011) o resgate do passado pela memória é o ponto de partida para o conhecimento. Produzir uma história de vida, e dar a ela a forma de uma biografia não se limita somente ao ato de registrar uma narrativa. Esse talvez seja o que há de mais visível ao se narrar uma vida. Ao narrar sobre a vida, toca-se em questões profundas, pois, mesmo sem perceber e sem conhecer os domínios ou os seus modos de uso, nos sentimos intuitivamente confrontado a alguma coisa que se diz respeito a esfera íntima e privada.

Para Santos a importância de escrever uma biografia alimentar está nos:

“[...] relatos ligados a degustação que foram percebidos, embora o tempo possa querer amortecer essas lembranças, a documentação é algo que possa ser relatada e que quando lida, irá trazer à tona aqueles momentos passados."

No relato do acadêmico a importância de escrever parte do que se percebe na degustação, e que por meio do registro de lembranças como documento de história de vida, faz ressurgir o passado através de momentos. Assim Ackerman (apud Figueiredo, 2011) e Demeterco (1998) afirmam que a comida é "grande fonte de prazer, um mundo complexo de satisfação, tanto fisiológica quanto emocional, que guarda grande parte das lembranças de nossa infância”. A comida é uma linguagem que agrega representações que retrata a família, principalmente a mulher como mãe e dona-de-casa, repleta de 
simbolismos presente nas formas de comer (RIBEIRO, apud Figueiredo, 2011). Amon \& Menasche (2008) argumentam que a voz da comida cotidiana, em contraposição a comida dos rituais, narra negociações de sentido e afirma a identidade de uma comunidade tanto quanto as suas transformações, em decorrência da convivência com outros grupos sociais.

As histórias que a comida de um outro lugar conta no lugar que a hospeda resgata também a memória do lugar de origem. Ao mesmo tempo em que reafirmam e reconstroem essa memória para gerações futuras da comunidade, as narrativas da comida podem incorporar novos traços à memória. As narrativas da comida sedimentam e transformam a identidade, o sistema de pertencimentos e as visões de mundo da comunidade no novo contexto. Tratamos, portanto, da memória social e daquilo que a memória singular pode resgatar dela.

\section{CONSIDERAÇÕES FINAIS}

Uma característica presente em várias produções, cada uma com sua singularidade e maneiras de lidar com o enunciado da pergunta, foi a utilização de uma estratégia pessoal para responder e abordar sobre o tema.

Focando a sutileza da resolução descrita pelo acadêmico, foi realizada uma leitura do modo como se produziu o significado para essa parte do enunciado e como escreveu sua resposta, transformando a pergunta e seguindo a sua lógica particular de pensar.

A análise narrativa se apresenta como uma estratégia metodológica ainda em construção, pelo menos em trabalhos de análise de produção escrita. Os trabalhos encontrados que analisaram produções escritas de acadêmicos, por meio dessa abordagem, ressaltaram que cada acadêmico tem um modo idiossincrático de lidar com o enunciado proposto.

Construiu-se um relato a respeito das particularidades de alguns acadêmicos por meio de uma leitura de sua produção escrita tendo como foco as singularidades, as particularidades, as lógicas particulares de cada produção.

Por fim, a forma expressa nas respostas narradas a pergunta sobre a importância de se escrever a biografia alimentar representou um modo particular de como o processo pedagógico, que procurou ser sensibilizador, foi realizado em nível de sala de aula, e como por meio das lembranças alimentares, os acadêmicos inscreveram na memória gustativa suas histórias de vida. 


\section{REFERÊNCIAS BIBLIOGRÁFICAS}

AMON, Denise; MENASCHE, Renata. Comida como narrativa da memória social. Sociedade e cultura, Goiânia, v. 11, n. 1, p. 13-21, jan./jun. 2008.

ASSUNCAO, Viviane Kraieski de. Comida de mãe: notas sobre alimentação, família e gênero. Caderno Espaço Feminino, Uberlândia, v. 19 n. 01, jan./jul. 2008.

BERNARDO, Teresinha. Memória em branco e negro: olhares sobre São Paulo. São Paulo: EDUC: Fapesp, 1998.

BRAUNE, Renata; FRANCO, Silva C. (2007). O que é Gastronomia. São Paulo. Brasiliense, 2007.

BRILLAT- SAVARIN, Jean- Anthelme. A fisiologia do gosto. Trad. Enrique Raul Renteria Guimaraes. Rio de Janeiro: Salamadra, 1989.

CARLOS, Suely Alves de. Identidade, memória e gênero nas obras literárias de Orlanda Amarílis e Clarice Lispector. 2009. 112 f. Dissertação (Mestrado em Letras) - Faculdade de Filosofia, Letras e Ciências Humanas, Universidade de São Paulo, São Paulo, 2009.

CARVALHO, I. C. M. Biografia, identidade e narrativa: elementos para uma análise hermenêutica. Horizontes Antropológicos. Porto Alegre, ano 9, n. 19, p. 283-302, 2003.

CORCAO, M. Memória gustativa e identidade: de Proust a cozinha contemporânea. Curitiba, UFPR, 2006. Artigo.

DAMATTA, Roberto. Sobre o simbolismo da comida no Brasil. O correio, Rio de Janeiro, v. 15 n. 7 , 22. jul. 1987.

DE ARRUDA, T. M. B. .; DE DEUS, A. I. S. . Educação estética: um percurso, uma trajetória, um convite a arte. Latin American Journal of Development, v. 3, n. 3, p. 1633-1641, 25 Jun. 2021.

DEMETERCO, S. M. da S. Doces lembranças: cadernos de receitas e comensalidade, Curitiba: 190050. 1998. 190 f. Dissertação (Mestrado em História do Brasil) - Setor de Ciências Humanas, Letras e Artes, Universidade Federal do Paraná, Curitiba, 1998. 190 f.

FIGUEIREDO, Samira Coutinho. Comida como narrativa: histórias de vida sobre experiências alimentares ao longo da vida. 2011. 118 f. Dissertação (Mestrado em Nutrição) - Escola de Nutrição, Universidade Federal da Bahia, Salvador, 2011.

FLANDRIN, Jean-Louis; MONTANARI, Massimo (Dir.). História da alimentação. São Paulo: Estação Liberdade, 1998.

JAPIASSU, Hilton; MARCONDES, Danilo (1996). Dicionário básico de filosofia. 3. ed. Rio de Janeiro: Jorge Zahar, 1996.

POLLAK, Michael. Memória, esquecimento e silêncio. Estudos históricos, Rio de Janeiro, v. 2, n. 3, 1992. 
REIS, D. G. dos. \& ANTONELLO, C. S. Ambiente de mudanças e aprendizagem nas organizações: contribuições da análise da narrativa. São Paulo. Gestão.org, v. 4, n. 2, p. 1-18, 2006.

SANTOS, J. R. V. dos \& DALTO, J. O. Sobre análise de conteúdo, análise textual discursiva e análise narrativa: investigando produções escritas na Matemática. Rio de Janeiro. ANAIS DO V SEMINÁRIO INTERNACIONAL DE PESQUISA EM EDUCAÇÃO MATEMÁTICA. p. 1 - 20, 2012.

SILVA, Paula Pinto e. Farinha, feijão e carne seca: um tripé culinário no Brasil colonial. São Paulo: Senac, 2005. 